\title{
Comparison of incidence of micro vascular complications in patients with youth onset type 1 and type 2 diabetes in India
}

PA Praveen', A Amutha ${ }^{2}$, K Singh ${ }^{3}$, U Shankar ${ }^{1}$, T Kaur ${ }^{4}$, R S Dhaliwal ${ }^{4}$, A K Das ${ }^{5}$, C S Yajnik ${ }^{6}$, V Mohan², Nikhil Tandon ${ }^{1}$

${ }^{1}$ All India Institute of Medical Sciences, New Delhi, India, ${ }^{2}$ Madras Diabetes Research Foundation, Chennai, India, ${ }^{3}$ Public Health Foundation of India, Gurugram, India, ${ }^{4}$ Indian Council of Medical Research, New Delhi, India, ${ }^{5}$ Pondicherry Institute of Medical Sciences, Puducherry, India, ${ }^{6}$ King Edward Memorial Hospital and Research Centre, Pune, India.

\section{Background}

There is a global deficiency in the literature pertaining to burden of complications in youth onset diabetes with a notable scarcity in the Asian countries.

\section{Objectives}

* To estimate the incidence of micro vascular complications (any form of diabetic retinopathy, neuropathy and nephropathy) among patients with youth onset diabetes in India.

* To compare the incidence of micro vascular complications among youth onset type 1 and type 2 diabetes .

\section{Methods}

* The study was conducted among a sub population of patients with youth onset type 1 and type 2 diabetes enrolled under the Registry of people with diabetes in India with young age at the onset (YDR).

* The baseline data of YDR patients collected between 1st January 2001 and 31st December 2012 and follow up data collected till 31st December 2014 were used to estimate the incidence of chronic diabetes complications.

* The final sample comprised of those who were aged >10 years at registration with no evidence of micro vascular complication of interest at baseline and had undergone at least one follow up visit during the above study period.

* The presence or absence of diabetic retinopathy was confirmed after a dilated fundus examination with direct ophthalmoscope confirmed by an experienced physician or ophthalmologist.

* The diabetic neuropathy status was assessed by clinical examination and monofilament test.

* Patients were labelled to have diabetic nephropathy if 24 hour urine protein excretion was greater than 500mg or urine albumin excretion was greater than $300 \mathrm{mg}$.

* Data of patients with type $1 \quad(n=799)$ and type $2(n=371)$ diabetes were analysed. The incidence rate of all the three micro vascular complications and that of presence of any one microvacular complication were significantly higher among patients with type 2 diabetes compared to type 1 diabetes (Table-1 \& Figure-1).

* $17.1 \%$ of patients with type 1 diabetes developed at least one micro vascular complication during the fourteen years of follow up.

* Among patients with type 2 diabetes, the proportion was much higher with $33.5 \%$ of the patients developing at least one micro vascular complication during the follow up period.

* In the multivariable Cox regression analysis, the high risk for incidence of micro vascular complications in type 2 diabetes patients was independent of the diabetes duration and clinical characteristics such as obesity, high blood pressure and glycaemic control at baseline (Table-2).

\begin{tabular}{|c|c|c|c|c|}
\hline & At risk (n) & Events(n) & Person years & $\begin{array}{c}\text { Incidence per } 1000 \\
\text { person years }\end{array}$ \\
\hline \multicolumn{5}{|c|}{ Diabetic retinopathy } \\
\hline Type 1 diabetes & 644 & 84 & 3291.3 & $25.5(20.6,31.6)$ \\
\hline Type 2 diabetes & 164 & 43 & 709.5 & $60.6(45.0,81.7)$ \\
\hline \multicolumn{5}{|c|}{ Diabetic neuropathy } \\
\hline Type 1 diabetes & 638 & 36 & 3321.6 & $10.8(7.8,15.0)$ \\
\hline Type 2 diabetes & 152 & 34 & 697.4 & $48.8(34.8,68.2)$ \\
\hline \multicolumn{5}{|c|}{ Diabetic nephropathy } \\
\hline Type 1 diabetes & 663 & 32 & 3473.3 & $9.2(6.5,13.0)$ \\
\hline Type 2 diabetes & 195 & 21 & 926.4 & $22.7(14.8,34.8)$ \\
\hline \multicolumn{5}{|c|}{$\begin{array}{l}\text { Any micro vascular } \\
\text { complication }\end{array}$} \\
\hline Type 1 diabetes & 716 & 122 & 3063.0 & $39.8(33.4,47.6)$ \\
\hline Type 2 diabetes & 224 & 75 & 750.6 & $99.9(79.7,125.3)$ \\
\hline
\end{tabular}

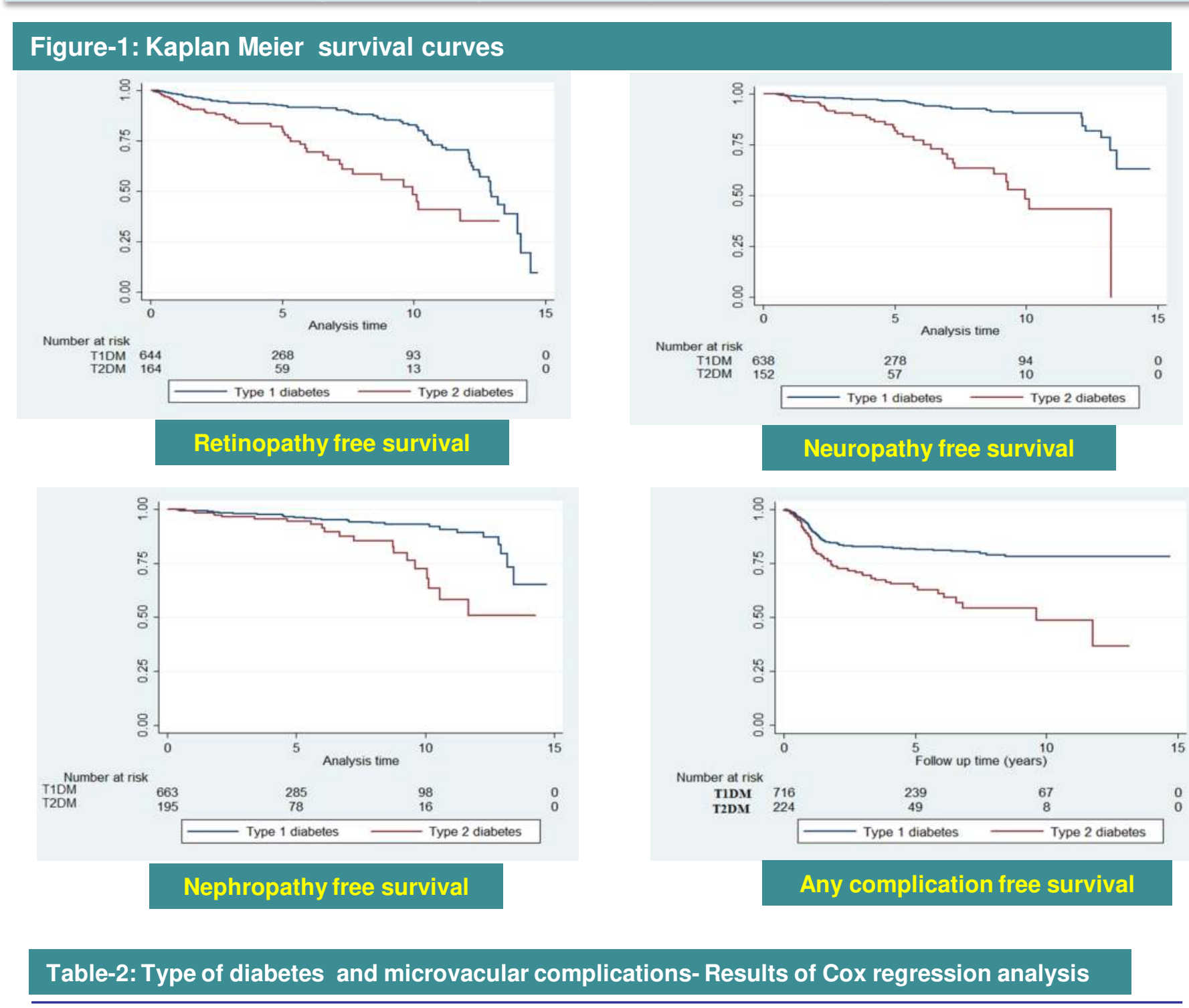

\begin{tabular}{lcc}
\hline & Adjusted $^{*}$ hazard ratio $\mathbf{( 9 5 \% ~ C l ) ~}$ & P value \\
\hline $\begin{array}{l}\text { Diabetic Retinopathy } \\
\text { Type 1 diabetes }\end{array}$ & Ref & \\
$\begin{array}{l}\text { Type 2 diabetes } \\
\text { Diabetic Neuropathy }\end{array}$ & $2.8(1.8,4.3)$ & $<0.0001$ \\
$\begin{array}{l}\text { Type 1 diabetes } \\
\text { Type 2 diabetes }\end{array}$ & Ref & \\
$\begin{array}{l}\text { Diabetic Nephropathy } \\
\text { Type 1 diabetes }\end{array}$ & $3.7(2.0,7.0)$ & $<0.0001$ \\
Type 2 diabetes & Ref & \\
\hline
\end{tabular}

*Adjusted for age, gender, duration of diabetes since diagnosis, obesity, high blood pressure and glycaemic control.

\section{Conclusions}

* The study reports a high incidence of microvascular complications among youth onset diabetes patients in India with an excess among youth onset type 2 diabetes.

* This is similar to that reported by the SEARCH Registry for youth onset diabetes in the US.

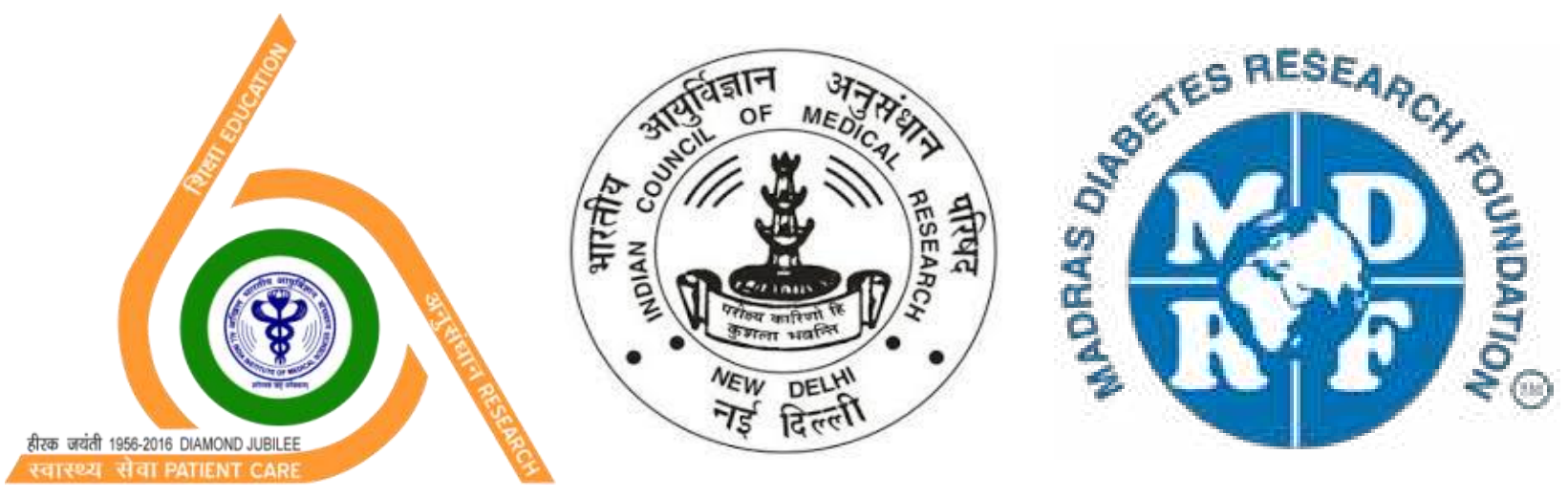

> The YDR registry was funded by the Indian Council of Medical Research, (ICMR) New Delhi, India $>$ PA Praveen received travel grant from the ICMR to attend the World Diabetes Congress-2017 